\title{
Levels of circulating endothelial cells and colony-forming units are influenced by age and dyslipidemia
}

\author{
Francesca I. Fabbri-Arrigoni ${ }^{1,2}$, Lindsey Clarke', Guosu Wang ${ }^{1}$, Marietta Charakida ${ }^{1}$, Elizabeth Ellins ${ }^{1,3}$, Neil Halliday ${ }^{1}$,
} Paul A. Brogan' ', John E. Deanfield', Julian P. Halcox ${ }^{1,3}$ and Nigel Klein'

BACKGROUND: The balance between endothelial injury and repair in childhood is poorly understood. We examined this relationship in healthy children, in adults, and in children with familial hypercholesterolemia (FH).

METHODS: Circulating endothelial cells (CECs) were measured as a marker of vascular injury, with vascular repair assessed by counting colony-forming units (CFUs), also known as endothelial progenitor cells.

RESULTS: CEC number increased with age. Children with FH had elevated CECs as compared with healthy children, with similar levels numerically to those found in healthy adults. CFU numbers were higher in healthy children than either healthy adults or children with FH. Endothelium-dependent vascular function, measured by flow-mediated dilatations, was positively associated with CFU number, even after adjustment for confounding risk variables.

CONCLUSION: Levels of CECs increase and CFUs decrease with age. In childhood, before the onset of clinically detectable cardiovascular dysfunction, children with a major risk factor for atherosclerotic disease have levels of these indexes of vascular injury and repair approaching those seen in adults.

A lthough atherosclerosis has long been regarded as a degenerative disorder associated with aging (1), considerable evidence now demonstrates that the underlying pathological process is highly modifiable and amenable to prevention. The vascular damage begins in childhood and develops silently for decades before clinical events such as myocardial infarction or stroke occur (2). Although clinical events rarely occur during childhood, subclinical atherosclerosis and the health of the vascular wall can be reliably detected at this early stage by noninvasive measures such as flow-mediated vasodilatation (FMD) and levels of circulating mature endothelial cells and endothelial microparticles in blood (3-5). This early progression, however, exists as a delicate balance between vascular endothelial injury and the endogenous ability to repair this damage.

Circulating cholesterol, particularly the low-density lipoprotein (LDL) cholesterol, is one factor that maintains a strong, continuous association with cardiovascular risk (6) from childhood onward, even at low concentrations. Only modest increases are typically seen in early life in relation to dietary habits, sedentary lifestyle, and obesity. More extreme elevation in cholesterol level during childhood is usually the consequence of genetic abnormalities (7).

A population of immature cells with the potential to recognize and repair sites of endothelial injury, identified in blood, may act as endogenous vascular repair mechanisms offsetting the damaging effect of risk factors (RFs) on the endothelium, potentially attenuating atherogenesis. These cells have been labeled as endothelial progenitor cells (EPCs) (8), and although the literature variably describes heterogeneous populations of cells, the exposure to RFs consistently appears to have an adverse impact on them. EPC number is not only associated with endothelium-dependent vasodilatation but is also predictive of cardiovascular prognosis independently of the conventional RF profile in higher risk patients (9-11).

Indeed, elevated levels of circulating LDL cholesterol in animals and adults with dyslipidemia are associated with decreased EPC number and function (12-14) that can increase following statin therapy and cholesterol reduction by nonpharmacological measures (15).

Currently, the role of these putative EPCs in childhood is not known, nor is it known how exposure to RFs during childhood influences their biology. We hypothesized that RFs for atherosclerosis, specifically aging and hypercholesterolemia, adversely affect the balance between vascular injury and repair.

In this study, we report changes in biomarkers of endothelial injury and repair in relation to age, hypercholesterolemia, and vascular function.

\section{RESULTS}

Relationship Between Age and Cellular and Vascular Parameters in Healthy Subjects

We studied 26 healthy children aged $10-18 y$ and 82 healthy adults aged $18-67 \mathrm{y}$. The baseline characteristics are summarized in Table 1. Systolic and diastolic blood pressure (BP); levels of total, LDL, and high-density lipoprotein cholesterol; and levels of triglycerides increased modestly with age (Table 1). 
Table 1. Baseline characteristics of healthy volunteers

\begin{tabular}{lccr}
\hline & \multicolumn{2}{c}{ Group (age, y) } & \\
\cline { 2 - 3 } & Child (10-18) & Adult (19-67) & P value \\
\hline Age median & $14(12-16)$ & $42(31-51)$ & \\
(interquartile range) & & & \\
Number of subjects & 26 & 82 & \\
Gender (\% male) & 34 & 37 & \\
WHR & $0.8 \pm 0.03$ & $0.83 \pm 0.02$ & 0.33 \\
Glucose, mmol/I & $4.7 \pm 0.06$ & $4.9 \pm 0.06$ & 0.133 \\
Total cholesterol, mmol/I & $4.1 \pm 0.13$ & $4.9 \pm 0.1$ & $<0.001^{*}$ \\
LDL cholesterol, mmol/I & $2.41 \pm 0.11$ & $2.94 \pm 0.09$ & $0.001^{*}$ \\
HDL cholesterol, mmol/I & $1.34 \pm 0.06$ & $1.53 \pm 0.05$ & $0.012^{*}$ \\
Triglycerides, mmol/I & $0.72(0.65-0.92)$ & $0.85(0.72-1.21)$ & $0.001^{*}$ \\
Systolic BP, mm Hg & $104 \pm 1.87$ & $117.8 \pm 1.6$ & $<0.001^{*}$ \\
Diastolic BP, mm Hg & $60.5 \pm 1.5$ & $71.0 \pm 1.04$ & $<0.001^{*}$
\end{tabular}

Values represent mean \pm SEM; age values represent median \pm interquartile range. Values compared between 10-18 and 19-67y-old age groups. Unpaired $t$-test between child age group and adult age group.

BP, blood pressure; HDL, high-density lipoprotein; LDL, low-density lipoprotein;WHR, waist-hip ratio.

*Significant differences between child and adult age groups, $P<0.05$.

Relationship Between Number of Colony-Forming Units and Age Colony-forming units (CFUs) were measured in 20 children and in 66 adults (Figure 1a). There was a significant correlation between CFU number and age $(r=-0.29, P=0.038)$ in the whole population (Figure 2a). Children had higher CFU numbers than adults (39 (13-59); 20 (9-31), $P=0.012$, median \pm interquartile range; children and adults, respectively).

Weight, waist size, glucose concentration, systolic and diastolic BP, and total, LDL, and high-density lipoprotein cholesterol levels did not correlate with CFU number. However, triglyceride $(r=-0.28, P=0.011)$ and LDL levels $(r=-0.31$, $P=0.005)$ correlated with CFU number. Moreover, the inverse relationship between $\mathrm{CFU}$ number and age remained after multivariable adjustment $(\beta=-0.32, P=0.03)$.

\section{Relationship Between Number of Circulating Endothelial Cells and Age}

Circulating endothelial cell (CEC) number increased with age in the entire cohort $(r=0.44, P<0.005)$. CEC numbers were also greater in adults than in children $(44$ (17-80) vs. 16 (14-32) median \pm interquartile range; children vs. adults, respectively, $P<0.001$ ) (Figure 3 ). The relationship between age and CEC number in healthy subjects remained after multivariable adjustment for vascular RFs, $(\beta=0.703, P<0.001)$.

\section{Relationships Between Age, Vascular Measures, CFU Number,} and CEC Number

To explore these relationships across the whole cohort, multiple regression analyses were conducted. A strong inverse relationship between FMD and age existed in the entire cohort, including children, after adjusting for baseline arterial diameter as well as gender and modifiable RFs in the model $(\beta=$ $0.453, P<0.001)$.
A significant relationship was observed between CFU and FMD in the whole cohort $(r=0.238, P=0.038)$ (Figure $2 b$ ), which remained after multivariable adjustment for RFs and baseline brachial artery diameter $(\beta=0.245, P=0.019)$. However, no relationship was observed between CEC levels and FMD.

\section{The Influence of Familial Hypercholesterolemia on Vascular and Cellular Parameters in Childhood \\ We studied 26 control children, eight of whom were unaffected siblings of FH patients, and 29 children with FH. Baseline characteristics are summarized in Table 2. Total and LDL cho- lesterol levels were greatly elevated and systolic BP was slightly higher in FH children.}

\section{CFU Number and CEC Number in Childhood FH}

CFU numbers were greatly reduced in the FH group as compared with healthy children $(12(4-36)$ vs. 39 (13-59), median \pm interquartile range, respectively, $P=0.028$ ) (Figure 4a). Moreover, multivariable analyses demonstrated a significant association between $\mathrm{CFU}$ and $\mathrm{FH}$ after adjusting for age, gender, and $\mathrm{BP}$ in the model $(\beta=0.357, P=0.045)$.

Children with $\mathrm{FH}$ also had elevated CEC levels as compared with age-matched controls (36 (16-161) vs. 16 (14-32), median \pm interquartile range, respectively, $P=0.031$ ) (Figure $4 b$ ).

\section{Relationships Between Vascular Measures, CFU Number, and CEC Number in Childhood Familial Hypercholesterolemia}

FMD was similar in healthy children and those with FH (6.9 (4.3-8.4) vs. 7.0 (3.7-9.67), $P=0.79$, median \pm interquartile range, respectively). No relationships between $\mathrm{CFU}$ number, CEC number, and vascular parameters were found in children with FH.

\section{DISCUSSION}

Our study is the first to examine the relationships between CFU number, CEC number, and vascular dysfunction in healthy aging from childhood to adulthood and in children with $\mathrm{FH}$. We have shown that the number of EPCs declines with age with a concomitant increase in CEC number, a recognized marker of endothelial injury. Consistent with previous data in adults with a range of RFs, we also found an independent relationship between CFU number and endothelial function in a healthy population, including children. This is in agreement with the concept that maintaining the balance between vascular injury and repair becomes more challenging with advancing age.

We have also found that children with $\mathrm{FH}$ have CFU and CEC levels similar to those found in adults, implying that exposure to this vascular RF has an adverse impact on endothelial homeostasis even at an early stage of life. Although our sample number is relatively small, the only RF that differed between healthy and FH children was the LDL cholesterol level, suggesting that this RF alone is sufficient to account for the raised CEC counts in FH children that were similar to the levels in adult participants, who have greater risk of cardiovascular disease risk than control children. 

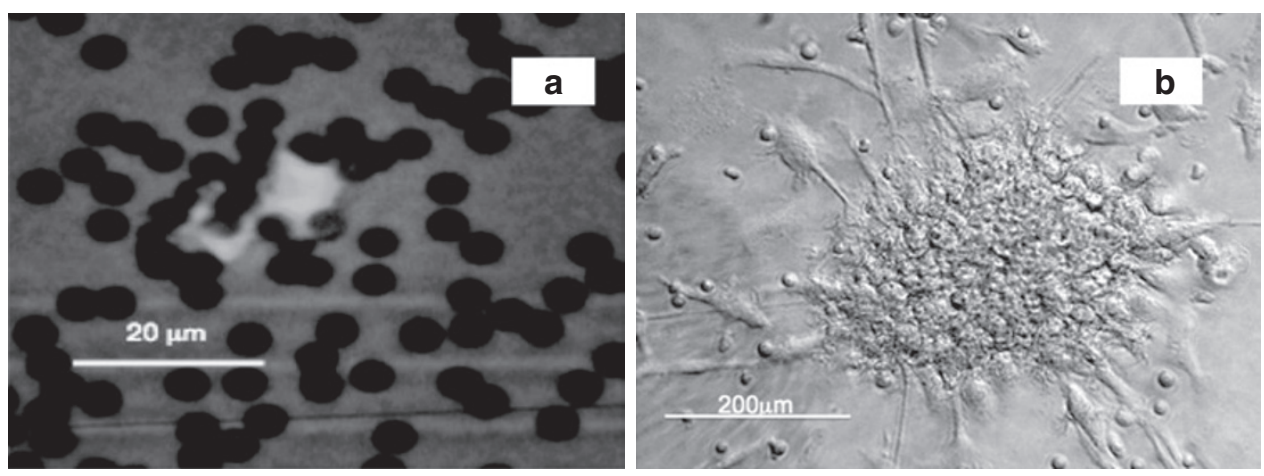

Figure 1. Enumeration of cell types. (a) Immunomagnetic beads coated with CD146 were incubated with whole blood, then adherent cells stained with fluorescein isothiocyanate-conjugated Ulex. Ulex bright cells with more than five beads attached and $>10 \mu \mathrm{m}$ in size were considered as circulating endothelial cells. (b) Phase-contrast image of a colony-forming unit (CFU). Nonadherent cells were selected from peripheral blood mononuclear cells cultured for $2 \mathrm{~d}$. They were grown in culture medium supplemented with cytokines and growth factors at $37^{\circ} \mathrm{C}$ and $5 \% \mathrm{CO}_{2}$ for $7 \mathrm{~d}$, and $\mathrm{CFUs}$ were then counted.
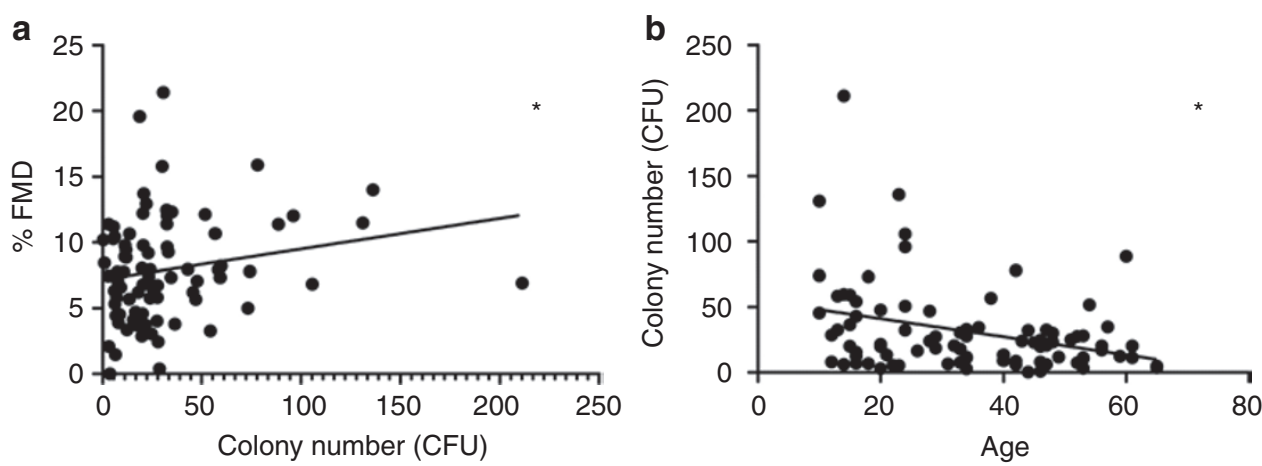

Figure 2. Alterations in colony-forming unit (CFU) number with age and with \% flow-mediated vasodilatation (FMD) in healthy subjects. (a) CFUs decreased with age starting from the age of 10 to $67 \mathrm{y}\left(r=-0.287,{ }^{*} P=0.007\right)$. Furthermore, (b) the increase in CFU number was associated with an augmented ability to vasodilatate $(\% \mathrm{FMD})(r=0.238, * P=0.038)$.

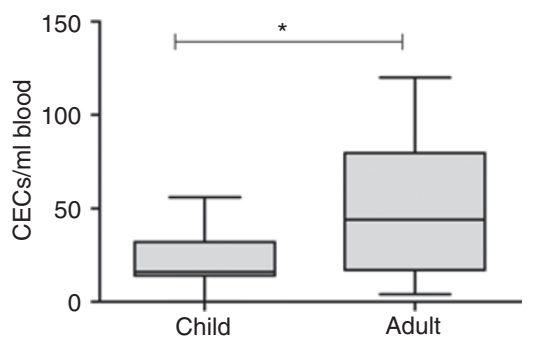

Figure 3. Alterations in circulating endothelial cell (CEC) number with age in healthy subjects. CEC number, which is known to represent endothelial damage and apoptosis, was greater in adults (19-67y) than in children (10-18y) 44 (17-80) vs. 16 (14-32) median \pm interquartile range; children vs. adults, respectively; ${ }^{*} P<0.001$ represents significant difference between adults and children.

There are still very limited data on these markers of endothelial damage and repair in healthy children. Our data are consistent with, and extend the implications of, previous studies that have demonstrated a decrease in CFU number with age (16) and shown increased concentrations of circulating angiogenic cell populations in children (17). Our data also demonstrate that with hypercholesterolemia, CFU numbers are lower in children with FH than in healthy age-matched children and are of a similar level to those seen in adults.
There is considerable controversy surrounding the true nature of EPCs and the significance of their numbers in humans. Since they were first discovered (18), a number of distinct populations of EPCs have been identified and defined. The phenotpye of our colonies was found be composed of hematopoietic cells enriched with $\mathrm{T}$ cells and monocytes/macrophages (data not shown) and is therefore an assay to measure cell-cell interactions rather than a postnatal primary vasculogenic cell population $(8,19)$.

In humans, it has been difficult to definitively demonstrate that EPCs of any phenotype directly replace endothelial cells in vivo, although cells of recipient origin have been identified within the coronary arterial endothelium in biopsy samples from heart transplant patients (20). Moreover, the absence of bone marrow-derived cells in the endothelium of atherosclerotic mouse plaques in a bone marrow transplant model has recently called into question how EPCs contribute to endothelial maintenance in vivo (21) despite evidence that cell transplantation accelerates endothelial healing in vascular injury models (22).

Nonetheless, the morphological identification of the CFUs or CFU endothelial cells (23) used here has been consistently identified as a predictive biomarker for disease $(9,10)$.

Indeed, our observations that CFU numbers fall from childhood into adulthood and that children with FH have fewer 
CFUs are consistent with the opinion that an increased vascular risk with aging and early exposure to lipid abnormalities may in part be explained by reduced CFU numbers $(3,12)$. It has also been suggested that the phenotype of these cells may be altered following chronic exposure to LDL, supported by data from in vitro studies demonstrating augmented senescence and a decreased capacity to form tubules in the presence of oxidized LDL $(13,14)$.

Studies in adults have consistently demonstrated a strong association between classical RFs and the numbers of both CFUs and CECs, suggesting a relevant biological link between RFs, these cells, and progression of vascular injury $(9,10,12,24-$ 28), although the causal relationship and extent of residual confounding by other influences remain to be determined.

Numbers of CECs increased with healthy aging from childhood and with childhood FH in our study, extending previous observations in healthy adults (29). There are a number

Table 2. Baseline characteristics of child cohorts

\begin{tabular}{|c|c|c|c|}
\hline & \multicolumn{2}{|c|}{ Group (age, y) } & \multirow[b]{2}{*}{$P$ value } \\
\hline & Child (10-18) & $\mathrm{FH}(10-18)$ & \\
\hline $\begin{array}{l}\text { Age median } \\
\text { (interquartile range) }\end{array}$ & $14(12-16)$ & $12(11-13)$ & \\
\hline Number of subjects & 26 & 29 & \\
\hline Gender (\% male) & 34 & 49 & \\
\hline WHR & $0.8 \pm 0.03$ & $0.85 \pm 0.18$ & 0.22 \\
\hline Glucose, $\mathrm{mmol} / \mathrm{l}$ & $4.7 \pm 0.06$ & $4.76 \pm 0.07$ & 0.76 \\
\hline Total cholesterol, $\mathrm{mmol} / \mathrm{l}$ & $4.1 \pm 0.13$ & $7.06 \pm 0.33$ & $<0.001^{*}$ \\
\hline LDL cholesterol, mmol// & $2.41 \pm 0.11$ & $5.29 \pm 0.31$ & $<0.001^{*}$ \\
\hline HDL cholesterol, mmol/l & $1.34 \pm 0.06$ & $1.45 \pm 0.05$ & 0.19 \\
\hline Triglycerides, mmol/l & $0.72(0.65-0.92)$ & $0.79(0.6-1.1)$ & 0.49 \\
\hline Systolic BP, mm Hg & $104 \pm 1.87$ & $110.6 \pm 2.50$ & $0.02 *$ \\
\hline Diastolic BP, mm Hg & $60.5 \pm 1.5$ & $62.7 \pm 1.9$ & 0.366 \\
\hline
\end{tabular}

Values represent mean $\pm \mathrm{SEM}$; age values represent median \pm interquartile range. Values compared between 10-18y-old healthy and FH children. Unpaired $t$-test between child age group and FH group.

$\mathrm{BP}$, blood pressure; FH, familial hypercholesterolemia; HDL, high-density lipoprotein; LDL, low-density lipoprotein, WHR, waist-hip ratio.

*Significant values, $P<0.05$.

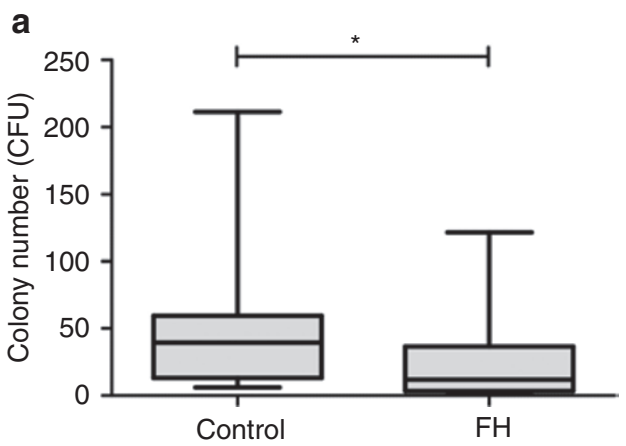

of different ways of measuring CECs, and comparing absolute numbers of CECs between different studies can be problematic because of the inherent variability in the techniques used. We used a previously validated method that provides a robust characterization of these cells and also fragments of senescent endothelial cells that may be lost using flow cytometric methods (3). Circulating markers of endothelial cell damage/ apoptosis, such as CECs, are measureable in healthy adults and children who are "at risk" for cardiovascular disease (30); for example, levels of CECs are elevated in very young children with irreversible pulmonary hypertension (31) and in children with vasculitis (3). Consequently, increased CEC levels are consistent with an increased endothelial cell turnover as a result of greater demand on the systems that maintain integrity of the vascular endothelium. Considered together with the lower CFU numbers, these CEC data are consistent with an adverse shift in the balance of endothelial injury and repair promoting a more rapid progression of disease observed with aging and $\mathrm{FH}(32,33)$.

The relationship between endothelium-dependent vasomotor function and age was unclear and difficult to determine because of the continuously altered arterial diameter from childhood to adulthood. Furthermore, in contrast to previous reports (34), vascular function in children with FH was no different from that in healthy children. It is likely that the recruited children with FH were "healthier" than subjects recruited to previous studies. Although they were not receiving statins, all children were managed in a specialist clinic where multiple healthy-lifestyle measures are promoted. The preserved endothelial vasomotor function observed in our FH group suggests that in childhood vascular injury induced by one or more RFs may still be compensated for, but compensatory factors are unlikely to be sufficient in the presence advancing age and increasing RF burden.

Nevertheless, the association between CFU numbers and FMD, even following adjustment for the global RF profile, remained consistent with previous reports and supports the hypothesis that these cells are influenced by RFs and implicated in the maintenance of a healthy endothelium (9).

Efforts to modulate this balance of injury and repair may prove to be an important means of preventing or reversing

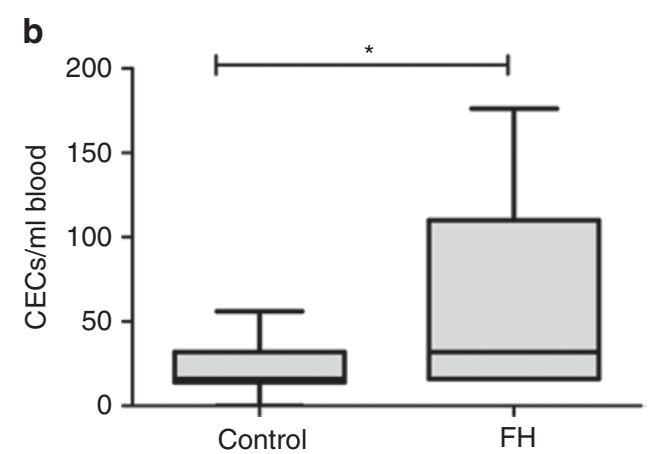

Figure 4. Alterations in colony-forming units (CFUs) and circulating endothelial cells (CECs) in children with familial hypercholesterolemia (FH). (a) Numbers of CFUs were reduced in FH children compared with healthy children (12 (4-36) vs. $39(13-59), P=0.028)$. Conversely, the numbers of CECs in children with FH were greater than those found in age-matched controls (36 (16-161); 16 (14-32), $P=0.031)$ (b). Data presented as median \pm interquartile range; ${ }^{*} P<0.05$ represents significant difference between healthy children and children with $\mathrm{FH}$. 
vascular injury, as exercise can elevate EPC levels $\left(\mathrm{CD} 133^{+} /\right.$ $\mathrm{KDR}^{+}$and $\mathrm{CD}^{2} 4^{+} / \mathrm{KDR}^{+}$cells) in children (35). This simple and effective means of enhancing vascular repair mechanisms may supplement the established benefits of exercise on weight, metabolic parameters, and general fitness and is likely to be of greatest incremental value in children with known RFs.

We conclude, using aging and childhood $\mathrm{FH}$ as models of increased cardiovascular risk, that subclinical endothelial pathophysiology is detectable at an early stage in life through the measurement of CFUs and CECs, even before functional vascular changes have become apparent, although a relationship between CFU numbers and FMD remains. Other disease states in children that are also associated with accelerated vascular injury from early life, such as obesity (36), chronic inflammatory disease or infection (37), and renal failure (38), would be amenable to similar analyses. Early detection of endothelial and vascular injury in these diseases could provide the information necessary to implement global and specific interventions that include exercise, dietary modification, and novel pharmacological approaches for improvement of longterm cardiovascular outcomes.

\section{METHODS}

\section{Study Population}

We conducted two studies. The first examined the relationship between age and indexes of vascular injury and repair in healthy individuals from childhood onward. The second was a case-control study exploring the impact of $\mathrm{FH}$ on these parameters during childhood. The study was approved by the Great Ormond Street Hospital for Children NHS Trust and the Institute of Child Health Research Ethics Committee, and informed consent was obtained from all the subjects. All the procedures were undertaken in accordance with national and institutional guidelines.

Participants underwent assessment of BP and anthropometric parameters (height, weight, and body mass). CFU assays were performed as previously described $(9,39)$. Briefly, $5 \times 10^{6}$ peripheral blood mononuclear cells per well were cultured in six-well fibronectin-coated plates containing RPMI (Gibco, Invitrogen, Carlsbad, CA) supplemented with $20 \%$ fetal calf serum (FCS; Imclone, New York, NY) and antibiotics. After $2 \mathrm{~d}$, the nonadherent cell population present in the supernatant was selected, and these cells were cultured at a concentration of $1 \times 10^{6} /$ well in fibronectin-coated 24 -well plates containing the following culture media (MCDB 131 medium; Invitrogen) supplemented with: L-glutamine, $50 \mathrm{ng} / \mathrm{ml}$ endothelial cell growth serum (Sigma-Aldrich, St Louis, MO), $20 \mathrm{ng} / \mathrm{ml}$ vascular endothelial growth factor (R\&D Systems, Boston, MA), $5 \mathrm{ng} / \mathrm{ml}$ basic human fibroblast growth factor, $20 \%$ fetal bovine serum (Imclone), $5 \mathrm{U} / \mathrm{ml}$ heparin, $100,000 \mathrm{U} / \mathrm{ml}$ penicillin, and $100,000 \mathrm{mg} / \mathrm{ml}$ streptomycin (39). All cells were cultured at $37^{\circ} \mathrm{C}$ and $5 \% \mathrm{CO}_{2}$, and the media were changed after $4 \mathrm{~d}$.

After an additional $7 \mathrm{~d}$ of culture, the cells were washed gently with warmed media, and the number of colonies in each well was counted using a phase-contrast microscope at $\times 100$ magnification (Leica Axiovert; Leica Microsytems, Wetzlar, Germany). A CFU was defined as a central core of round cells with more-elongated cells at the periphery $(9,39)$. Colony counting and preparation was carried out with an interobserver correlation of 0.95 for the final colony count.

\section{Circulating Endothelial Cells}

CECs were extracted and enumerated in nested subgroups of healthy subjects and children with $\mathrm{FH}$ using a protocol previously described by our group (3). Briefly, $1 \mathrm{ml}$ of blood collected in EDTA tubes was mixed with $1 \mathrm{ml}$ buffer $(0.1 \%$ sodium azide, $0.6 \%$ sodium citrate, $0.1 \%$ bovine serum albumin in phosphate-buffered saline) and $20 \mu \mathrm{l} \mathrm{FCR}$ blocking agent (Miltenyi Biotec, Cologne, Germany). To this we added
$50 \mu \mathrm{l}$ of a preparation of Dynal beads (Dynal Biotech, Bromborough, Wirral, UK) linked to CD146 (Biocytex, Marseille, France), and the mixture was incubated for $30 \mathrm{~min}$ at $4{ }^{\circ} \mathrm{C}$. The cells bound to CD146 immunomagnetic beads were separated using a magnet (MPC-l, Dynal Biotech) and washed three times in a buffer before resuspension in $100 \mu \mathrm{l}$ of buffer containing $2 \mathrm{mg} / \mathrm{ml}$ fluorescein isothiocyanate-labeled Ulex (Ulex Europus Lectin, Sigma-Aldrich). These cells were incubated in the dark at room temperature for $1 \mathrm{~h}$ before washing three times in buffer and finally resuspended in $200 \mu \mathrm{l}$ buffer. Cells were counted using a Nageotte chamber and a fluorescent microscope (Leica Microsystems). Brightly fluorescent cells $>10 \mu \mathrm{M}$ in diameter that had more than five CD146 beads attached were considered CECs $(3,29)$. CEC counting was carried out with an interobserver correlation of 0.95 for the final CEC count.

\section{Noninvasive Vascular Studies}

All studies were performed in a temperature-controlled vascular laboratory by a trained operator. Studies commenced after an acclimatization period of at least $15 \mathrm{~min}$.

\section{Brachial Artery Vasomotor Function}

High-resolution ultrasound imaging with an Acuson 5- to $10-\mathrm{MHz}$ linear probe (Acuson, Mountain View, CA) was used to assess flowmediated dilatation as previously reported (40). Brachial artery diameter was measured offline by an automatic edge-detection system (Brachial Tools, Medical Imaging Applications, Coralville, IA) and expressed as a percentage change from baseline diameter. Dopplerderived flow measurements (using a pulsed-wave Doppler signal at a $70^{\circ}$ angle) were also obtained continuously. The increase in blood flow after the release of the cuff was expressed as a percentage change from the baseline flow.

\section{Statistics (Data Analysis)}

Data are expressed as mean \pm SE of the mean or median (interquartile range) for nonparametric data, unless otherwise stated. In descriptive analyses, parametric summary statistics and significance tests were used when the data were normally distributed. Nonparametric tests were used for analysis of gender, triglycerides, CFU number, and CEC data. The European reference curves were used for $z$-scores.

Univariate comparisons between groups were analysed by $t$-test for normally distributed data and Mann-Whitney $U$-test or KruskalWallis test for nonparametric data. The $\chi^{2}$ test was used to assess differences in gender.

Bivariate correlations were determined using Pearson or Spearman correlation coefficients as appropriate. Multivariable logistic regression analyses were performed to explore relationships between age and number of CFUs and/or vascular measures with adjustments for potential confounders (gender, waist circumference, systolic BP, fasting glucose, and lipid levels). All statistical analyses were performed with SPSS, version 16 (SPSS, Chicago, IL).

\section{ACKNOWLEDGMENTS}

We thank the Vasculopathy Consortium at the Institute of Child Health, which helped with the endothelial assays and with patient recruitment.

\section{STATEMENT OF FINANCIAL SUPPORT}

The work was supported by the British Heart Foundation (grant PG/04/081/17384).

\section{REFERENCES}

1. Grundy SM. Age as a risk factor: you are as old as your arteries. Am J Cardiol 1999;83:1455-7, A7.

2. Dawber TR. The Framingham Study: The Epidemiology of Atherosclerotic Disease. Cambridge, MA: Harvard University Press, 1980.

3. Clarke LA, Shah V, Arrigoni F, et al. Quantitative detection of circulating endothelial cells in vasculitis: comparison of flow cytometry and immunomagnetic bead extraction. J Thromb Haemost 2008;6: 1025-32.

4. Deanfield J, Donald A, Ferri C, et al. Endothelial function and dysfunction. Part I: Methodological issues for assessment in the different 
vascular beds: a statement by the Working Group on Endothelin and Endothelial Factors of the European Society of Hypertension. J Hypertens 2005;23:7-17.

5. Järvisalo MJ, Jartti L, Näntö-Salonen K, et al. Increased aortic intima-media thickness: a marker of preclinical atherosclerosis in high-risk children. Circulation 2001;104:2943-7.

6. Murray C, Lopez A. The World Health Report 2002: Reducing Risks, Promoting Healthy Life. Geneva, Switzerland: World Health Organization, 2002:230.

7. Virkola K, Pesonen E, Akerblom HK, Siimes MA. Cholesterol and carotid artery wall in children and adolescents with familial hypercholesterolaemia: a controlled study by ultrasound. Acta Paediatr 1997;86:1203-7.

8. Yoder MC, Mead LE, Prater D, et al. Redefining endothelial progenitor cells via clonal analysis and hematopoietic stem/progenitor cell principals. Blood 2007;109:1801-9.

9. Hill JM, Zalos G, Halcox JP, et al. Circulating endothelial progenitor cells, vascular function, and cardiovascular risk. N Engl J Med 2003;348:593600.

10. Werner N, Kosiol S, Schiegl T, et al. Circulating endothelial progenitor cells and cardiovascular outcomes. N Engl J Med 2005;353:999-1007.

11. Schmidt-Lucke C, Rössig L, Fichtlscherer S, et al. Reduced number of circulating endothelial progenitor cells predicts future cardiovascular events: proof of concept for the clinical importance of endogenous vascular repair. Circulation 2005;111:2981-7.

12. Vasa M, Fichtlscherer S, Adler K, et al. Increase in circulating endothelial progenitor cells by statin therapy in patients with stable coronary artery disease. Circulation 2001;103:2885-90.

13. Imanishi T, Hano T, Matsuo Y, Nishio I. Oxidized low-density lipoprotein inhibits vascular endothelial growth factor-induced endothelial progenitor cell differentiation. Clin Exp Pharmacol Physiol 2003;30:665-70.

14. Imanishi T, Hano T, Sawamura T, Nishio I. Oxidized low-density lipoprotein induces endothelial progenitor cell senescence, leading to cellular dysfunction. Clin Exp Pharmacol Physiol 2004;31:407-13.

15. Croce G, Passacquale G, Necozione S, Ferri C, Desideri G. Nonpharmacological treatment of hypercholesterolemia increases circulating endothelial progenitor cell population in adults. Arterioscler Thromb Vasc Biol 2006;26:e38-9.

16. Hoetzer GL, MacEneaney OJ, Irmiger HM, et al. Gender differences in circulating endothelial progenitor cell colony-forming capacity and migratory activity in middle-aged adults. Am J Cardiol 2007;99: 46-8.

17. Jie KE, Goossens MH, van Oostrom O, Lilien MR, Verhaar MC. Circulating endothelial progenitor cell levels are higher during childhood than in adult life. Atherosclerosis 2009;202:345-7.

18. Asahara T, Murohara T, Sullivan A, et al. Isolation of putative progenitor endothelial cells for angiogenesis. Science 1997;275:964-7.

19. Hirschi KK, Ingram DA, Yoder MC. Assessing identity, phenotype, and fate of endothelial progenitor cells. Arterioscler Thromb Vasc Biol 2008;28:1584-95.

20. Minami E, Laflamme MA, Saffitz JE, Murry CE. Extracardiac progenitor cells repopulate most major cell types in the transplanted human heart. Circulation 2005;8:19.

21. Hagensen MK, Shim J, Thim T, Falk E, Bentzon JF. Circulating endothelial progenitor cells do not contribute to plaque endothelium in murine atherosclerosis. Circulation 2010;121:898-905.
22. Gulati R, Jevremovic D, Witt TA, et al. Modulation of the vascular response to injury by autologous blood-derived outgrowth endothelial cells. Am J Physiol Heart Circ Physiol 2004;287:H512-7.

23. Gehling UM, Ergün S, Fiedler W. CFU-EC: how they were originally defined. Blood 2007;110:1073.

24. Werner N, Wassmann S, Ahlers P, et al. Endothelial progenitor cells correlate with endothelial function in patients with coronary artery disease. Basic Res Cardiol 2007;102:565-71.

25. Fadini GP, Coracina A, Baesso I, et al. Peripheral blood CD34+KDR+ endothelial progenitor cells are determinants of subclinical atherosclerosis in a middle-aged general population. Stroke 2006;37:2277-82.

26. Westerweel PE, Visseren FL, Hajer GR, et al. Endothelial progenitor cell levels in obese men with the metabolic syndrome and the effect of simvastatin monotherapy vs. simvastatin/ezetimibe combination therapy. Eur Heart J 2008;29:2808-17.

27. Tepper OM, Galiano RD, Capla JM, et al. Human endothelial progenitor cells from type II diabetics exhibit impaired proliferation, adhesion, and incorporation into vascular structures. Circulation 2002;106:2781-6.

28. Fadini GP, de Kreutzenberg S, Agostini C, et al. Low CD34+ cell count and metabolic syndrome synergistically increase the risk of adverse outcomes. Atherosclerosis 2009;207:213-9.

29. Woywodt A, Blann AD, Kirsch T, et al. Isolation and enumeration of circulating endothelial cells by immunomagnetic isolation: proposal of a definition and a consensus protocol. J Thromb Haemost 2006;4:671-7.

30. Bulut D, Tüns H, Mügge A. CD31+/Annexin V+ microparticles in healthy offsprings of patients with coronary artery disease. Eur J Clin Invest 2009;39:17-22.

31. Smadja DM, Gaussem P, Mauge L, et al. Circulating endothelial cells: a new candidate biomarker of irreversible pulmonary hypertension secondary to congenital heart disease. Circulation 2009;119:374-81.

32. Wiegman A, de Groot E, Hutten BA, et al. Arterial intima-media thickness in children heterozygous for familial hypercholesterolaemia. Lancet 2004;363:369-70.

33. Smilde TJ, van Wissen S, Wollersheim H, Kastelein JJ, Stalenhoef AF Genetic and metabolic factors predicting risk of cardiovascular disease in familial hypercholesterolemia. Neth J Med 2001;59:184-95.

34. Sorensen KE, Celermajer DS, Georgakopoulos D, Hatcher G, Betteridge DJ, Deanfield JE. Impairment of endothelium-dependent dilation is an early event in children with familial hypercholesterolemia and is related to the lipoprotein(a) level. J Clin Invest 1994;93:50-5.

35. Walther C, Adams V, Bothur I, et al. Increasing physical education in high school students: effects on concentration of circulating endothelial progenitor cells. Eur J Cardiovasc Prev Rehabil 2008;15:416-22.

36. Reilly JJ, Methven E, McDowell ZC, et al. Health consequences of obesity. Arch Dis Child 2003;88:748-52.

37. Charakida M, Donald AE, Green $\mathrm{H}$, et al. Early structural and functional changes of the vasculature in HIV-infected children: impact of disease and antiretroviral therapy. Circulation 2005;112:103-9.

38. Kari JA, Donald AE, Vallance DT, et al. Physiology and biochemistry of endothelial function in children with chronic renal failure. Kidney Int $1997 ; 52: 468-72$.

39. Arrigoni FI, Matarin M, Thompson PJ, et al. Extended extraocular phenotype of PROM1 mutation in kindreds with known autosomal dominant macular dystrophy. Eur J Hum Genet 2011;19:131-7.

40. Donald AE, Halcox JP, Charakida M, et al. Methodological approaches to optimize reproducibility and power in clinical studies of flow-mediated dilation. J Am Coll Cardiol 2008;51:1959-64. 